\title{
REPRESENTAÇÃO SOCIAL: PRAXIS E CONHECIMENTO SOBRE O DESENVOLVIMENTO DA CRIANÇA ${ }^{1}$
}

Denize Cristina de Oliveira ${ }^{2}$ Augusta Thereza de Alvarenga ${ }^{3}$

OLIVEIRA, D.C.; ALVARENGA, A.T. Representação Social: Praxis e Conhecimento sobre o Desenvolvimento da Criança. Rev. Bras. Cresc. Des. Hum., São Paulo, III(2), 1993.

Resumo: O presente trabalho trata das representações sociais de mães e de profissionais de saúde sobre o processo de desenvolvimento infantil. O estudo das representações foi realizado por meio de análise de discursos, coletados em 54 entrevistas realizadas com mulheres usuárias de duas unidades básicas de saúde, localizadas na Grande São Paulo, e de 25 entrevistas efetuada.s com profissionais de formação variada atuando em programas de saúde dirigidos à criança.

As formas de estruturação do grupo familiar, os valores incorporados pela família e transmitidos aos filhos através do processo de socialização das crianças, a própria socialização como elemento importante no processo de crescimento e de desenvolvimento, foram alguns dos temas discutidos a partir da análise das entrevistas de mães.

No que se refere às práticas profissionais, destacam-se as relações de poder estabelecidas entre mulheres usuárias dos serviços e o grupo profissional a eles vinculados.

Busca-se contribuir para o processo de entendimento da dinâmica das relações estabelecidas entre os níveis de saber envolvidos nas práticas institucionais da Saúde Pública - o saber do senso comum, por um lado, o saber técnico profissional, por outro, além do conhecimento científico especializado do Setor.

Palavras-chave: representação, desenvolvimento, criança, saúde, serviços de saúde.

Summary: This study deals with the social representations of mothers and health professionals on the process of child development. It was carried out through an analysis of the discurse taken out of 54 interviews made with femals users of two basic health units in lhe Great São Paulo, State of São Paulo, Brazil; as well as out of 25 interviews carried out with profissionaals of diverse academic bakgrounds who were engaged in child health programmes in the above mentioned health units.

file structural forms taken by the famiiy group, the values incorporated by the famiiy and transmitted to its children through the process of socialization, and the socialization it self, as an important element in the process of growth and development, were some of themes

1 Trabalho elaborado a partir da Dissertação de Mestrado apresentada à Faculdade de Saúde Pública da Universidade de São E aulo, intitulada: "O desenvolvimento infantil e Suas representações: dimensões do saber técnico profissional e do senso comum” (OLIVEIRA, 1991).

2 Enfermeira, Mestre em Saúde Pública do Núcleo de Apoio à Cultura e Extensão Universitária do Crescimento e Desenvolvimento Hurnano - NACE-CDH da Faculdade de Saúde Públical/USP. End.: Av. Dr. Arnaldo, 715 - subsolo - sala 21 - São Paulo - SP CEP 01246-904 - Tel.: 851-3572.

3 Socióloga, Professora Doutora do Departamento de Saúde Matemo-Infantil da Faculdade de Saúde Pública/USP. 
discussed which have arisen from the analysis of the mothers' interviews.

Regarding the profissional practices, the relationships of power established between the women attending the health services and the professional health team working there were emphasized. These relationships were analysed from the theoretical framework of "social field" and "symbolic violence".

The conditions of production of knowiedge and the derived practices constituted the basic concern which can be seen through ali the study. The Author hopes, with this work, to contribute to the process of understanding the dynamics of the relationships established among the leveis of knowiedge involved in the institutional public heaith practices - the common sense knowiedge - on one side, the technicai and professionai knowiedge on the other side and, $f \sim$ naiily, the specific scientific knowiedge of the fieid of chiid deveiopment.

Key words: child, development, representation, heaith, heaith services.

\section{INTRODUÇÃO}

Dentro da proposta central deste trabalho, encontra-se a necessidade da área de Saúde Pública/Coletiva de redefinir a relação teoria prática contida nas estratégias de ação programática que norteiam as políticas no setor de assistência à criança.

O que se configura como aspecto fundamental é um desafio interdisciplinar, onde os conhecimentos das Ciências Humanas e Biológicas se configuram como instrumentos úteis à releitura do objeto "desenvolvimento infantil", objeto este que a partir da década de 80 tem se apresentado como campo de prioridade do setor saúde.

É neste contexto de interpenetração das diversas áreas de conhecimento que o presente trabalho se coloca.

A proposta de conhecer a noção de desenvolvimento infantil presente nas representações de dois grupos distintos, o de mulheres mães e o de profissionais permite, não apenas saber o que as mães e os profissionais de saúde pensam sobre o tema, mas possibilita, sobretudo, derivar deste conhecimento consequências teóricas, metodológicas, técnicas e ideológicas.

Problematizar um fato que faz parte do cotidiano buscando sua explicitação a partir da "teoria do senso comum" que lhe dá suporte, bem como fazer emergir representações técnico profissionais que sustentam a prática dos serviços de Saúde Pública, foi uma das maneiras de buscar o desvendamento de aspectos ideológicos que permeiam esse tipo de relação em dada realidade social, assim como de desvelar aspectos da relação teoria-praxis embutidos nas políticas públicas de assistência à criança.

A Saúde Coletiva tem tido dificuldades em abordar a questão do desenvolvimento infantil, apresentando propostas que ignoram seus princi- pais interlocutores, quais sejam, as famílias e os profissionais. Saber como esses dois grupos se aproximam e se opõem em determinado processo de relação constituiu uma proposta de estudo pertinente, tendo em vista a atual fase de conhecimento sobre o tema.

As possibilidades que se colocam para Ieitura e releitura dos dados levantados pela pesquisa são inúmeras, em função da riqueza do tema e de diferentes possibilidades de problematização do mesmo. Procurou-se, no presente trabalho, reconstruir a realidade pesquisada à luz da Psicologia, Antropologia e Sociologia, através de conceitos que possibilitassem a articulação das dimensões individual e coletiva presentes no processo de desenvolvimento infantil.

Disso advém o fato de que o desvendamento das representações sociais sobre o desenvolvimento infantil "f̧ala" das condições objetivas e subjetivas de existência vivenciadas pelas familias em estudo Acredita-se que a dinamica das desigualdades em saúde se inscreve igualmente nos sistemas de valores e de representações, configurando rclações especificas de poder entre profissionais e população.

$\mathrm{O}$ que se configura no presente momento é um desafio para o setor saúde, que consiste em desenhar politicas públicas de promoçãa à saúde da criança e, consequentemente, de seu crescimento e desenvolvimento, que procurem eliminar os pressupostos de base nos quais essas políticas se apoiam. Tais pressupostos podem ser sintetizados do seguinte modo: as políticas públicas de assistência à saúde são constituídas por um conjunto de ações fundamentadas no conhecimento científico, a serem operadas por profissionais de saúde, com vistas a produzir efeitos concretos nos objetos destas políticas - os usuários dos serviços de saiide - aos quais está reservado simplesmente o papel de cumprir as deter- 
minações dos profissionais de saúde, instrumentos estes da ação científica.

Na medida em que se constata que, tanto a população, quanto os profissionais têm representações próprias a respeito do desenvolvimento infantil e que estas interferem no desdobramento desse processo, as políticas públicas sobre o tema não podem se limitar a um catálogo de normas e procedimentos técnicos, mas devem Ievar em conta as representações dos atores sobre esse processo.

O conhecimento científico e, por implicação, o saber técnico profissional, são construidos no sentido da negação da ambigüidade do conceito de desenvolvimento infantil, buscando formas explicativas segmentadas e estanques desse processo.

No entanto, semanticamente, o conceito e a explicação do processo de desenvolvimento são ambiguos e polissêmicos, na medida em que não há consenso sobre uma definição ou sentido único, seja em nivel do conhecimento científico, do conhecimento técnico profissional ou do saber do senso comum.

Os contornos de uma nova praxis, portanto devem se dar no sentido de comportar a ambiguidade presente nos diversos níveis de conhecimentos como forma de oposição à segmentação e busca de uma prática que recupere a criança em sua totalidade.

\section{PERFIL DO ESTUDO E DOS SUJEITOS SOCIAIS SOB ANALISE}

O presente artigo repete a análise realizada a partir de 54 entrevistas realizadas com mães, que frequentaram duas unidades básicas de saúde da cidade de São Paulo e seus respectivos profissionais num total de 25 encarregados do atendimento das crianças.

As unidades de saúde caractcrizam-se pela prestação de atendimento primário contínuo à saúde da criança, pela localização e pelos perfis da população atendida. O primeiro serviço localizasse em região periférica da cidade, atendendo a uma população de migrantcs nordestinos, pauperizados e sub mpregados. $\mathrm{O}$ segundo, caracteriza-se como um Centro de Saúde Escola localizado em região central da cidade e atende a uma população heterogênea, na sua grande maioria moradora em cortiços, porém com um padrão de renda e ocupação diferenciados do serviço 1 . Ambos os serviços são governamcntais e prestam assistência gratuita à população.

Os Atores do Cotidiano
Ao esboçar o espaço do pensamento coletivo de mães sobre o processo do desenvolvimento infantil, buscou-se definir um "sistema articulado de unidades de sentido" que se decompõe em "núcleos estruturadores dos discursos", categorias, sub-categorias e grupos temáticos, conformando os pilares da "teoria do senso comum" subjacente aos depoimentos analisados.

O que se busca tratar, no presente trabalho, são os contornos desse sistema de significação que, no seu conjunto, desvendam as representações sociais construídas pelo grupo de mães entrevistadas.

Foram definidos três núcleos articuladores dos discursos que representam o eixo temático em torno do qual todos os depoimentos se agregam. São eles: Aspecto conceitual do desenvolvimento infantil; rede de relações estabelecidas com o desenvolvimento infantil e atribuição de conhecimento sobre o desenvolvimento da criança. A cada núcleo referido correspondcm categorias gerais e específicas, em função do conteúdo dos depoimentos analisados, que representam as unidades de sentido do pensamento coletivo. Tais unidades foram construídas a partir do conteúdo expresso nos depoimentos o que as caracteriza como categorias empíricas.

Observa-se nesta análise dois aspectos importantes: no plano horizontal, os depoimentos das mães não configuram sempre tipos puros e mutuamente exclusivos, apenas permitem realçar mais, uma ou outra das categorias de análise; no plano vertical, as categorias c os núcleos temáticos levantados não esgotam as possibilidades de análise do material empírico.

Trata-se, portanto da descrição de um dos modos possíveis de organizar e reconstituir a "teoria do senso comum" sobre o desenvolvimento infantil da população estudada.

\section{Os Atores Institucionais}

A análise dos discursos dos profissionais foi desenvolvida segundo o mesmo procedimento técnico da análise de discurso do senso comum.

Procurou-se definir os "espelhos" das categorias encontradas nas representações do senso comum no discurso técnico-profissional, uma vez que a orientação das entrevistas seguem um eixo comum nos dois grupos, buscando assim a confrontação dos dois níveis onde as representações foram analisadas.

Foram definidos 3 núcleos de articulação dos discursos, quais sejam: aspecto conceitual do desenvolvimento infantil, relações estabelecidas com o desenvolvimento e representações sobre as mães usuárias dos serviços de saúde. A cada 
núcleo estabelecido correspondem categorias empíricas gerais e específicas configurando, no seu conjunto, os contornos das representações sobre o desenvolvimento infantil.

A análise do material empírico foi, primeiramente, processada em separado, por unidade de saúde e categoria profissional; no entanto, as semelhanças encontradas justificaram a apresentação da análise em conjunto. Destaca-se que a variação nos níveis de formação dos profissionais e o fato de que muitos deles são mulheres-mães não foram significativos para a determinação das categorias, uma vez que seus discursos foram contidos a partir do papel social desempenho no momento da entrevista, ou seja, de agentes institucionais.

\section{REPRESENTAÇÕES DA REALIDADE: DISCURSO DO SENSO COMUM E DISCURSO TÉCNICO PROFISSIONAL}

\section{Representações Maternas e Profissionais: Perfil e Determinações}

Procurou-se trabalhar as representações de mães sobre o desenvolvimento de seus filhos na busca de elementos singulares que pudessem deixar transparecer alguns matizes do contexto social onde esse desenvolvimento se dá.

Ao definir a família como esse núcleo social, partiu-se de alguns pressupostos teóricos e de categorias empíricas presentes nas representações maternas. Adota-se aqui o referencial teórico onde a família é vista enquanto instituição social, um aparelho reprodutor ou na linguagem de ALTHUSSER (1980) - um “Aparelho ideológico de Estados. Nesta concepção, a família é responsável pela transmissão dos valores de classe.

Os primeiros anos de vida da criança (ou período denominado infância), são vividos, em geral, dentro do grupo familiar e este, por sua vez, é responsabilizado - e responsabiliza-se - pelo processo de "socializaçao" da criança, no interior do qual se inscreve o processo de desenvolvimento infantil.

Para a análise do papel da família nesse contexto, adota-se as colocações de GOMES (1988, p.49) onde afirma que a transformação do ser biológico em um ser social "implica em interiorizar e aprender a desempenhar os papéis sociais decorrentes de duas situações, de classe e de sexo”. Para a autora, essas situações são definidas porque é em função do trabalho que realiza e da posição ocupada pelo individuos como homem ou como mulher, que o mesmo se situa na estrutura social.

Tal aprendizagem só é possível se media- da por grupos sociais específicos responsáveis pela tarefa de garantir o processo de internalização de valores sociais de classe, capazes de reproduzir dada ordem sócio-cultural tipificadora de rcpresentações particulares.

Pensada neses termos, cabe à família, em função de suas características e inscrição em dada classe social, realizar essa mediação. Por implicação o grupo familiar pode ser visto também, em função do meio sócio-cultural específico que representa, na medida que domina certos aspectos do conteúdo cultural que, em termos particulares, caracteriza a sua classe e em tennos gerais, a sociedade da qual participa. A família representa o que, na linguagem de BOURDIEU (1989, 1974), se apresenta como “capital cultural”, capital este que a define enquanto um “campo social”, onde segundo ALVARENGA (1986) as condições concretas de existência imprimem formas típicas de crescimento e de desenvolvimento sob determinados moldes.

Na medida em que a mediação social realizada pelo grupo familiar consiste em tornar acessível, no cotidiano, a parcela do acervo cultural do grupo social a que pertence, isto é, aquilo que lhe é facultado, em função de sua condição de classe, o meio sócio-cultural do grupo familiar apresenta-se, em si mesmo, como determinado por tais condições.

Tal mediação se dá através do que BOURDIEU (1989) denomina de "habitus de classe”, entendido como as disposições duráveis que produzem as práticas, que orientam a ação. São normas e valores interiorizados desde a primeira infância, num duplo movimento (dialético) de interiorização da exterioridade e de exteriorização da interioridade. Para o autor, [as práticas maternas, familiares e institucionais] são, portanto, produto da relação dialética entre um habitus e um contexto, pois só é possível entender a ação em um espaço social definido, em um campo onde as posições dos agentcs encontram-se delimitadas”.

Dentro desse quadro teórico é que as representações das mães foram analisadas, a partir dos valores ideológicos que as revelam como categoria de pensamento do senso comum, em termos da forma de conceber, de entender a questão do desenvolvimento infantil. Tais representações desvelam, em suma, o "habitus" do "campo socal” família.

As categorias conceituais do desenvolvimento infantil podem ser interpretadas em relação a dois eixos básicos. No primeiro, estão as representações de mães que aproximam o desenvolvimento infantil de um processo natural e inespecífico, portanto, indeterminados na medida em que, na linguagens ordinária, “é tudo”. No 
segundo, encontram-se concepções específicas e claramente identificadas no conhecimento científico especializado (quer da área médica, quer da psicologia); essas representações organizam as vivências cotidianas em torno de conceitos como estímulos, saúde, inteligência, dentre outros. (Quadros 1, 2, 3)

No segundo eixo analítico, as representações apresentam-se como forma típica de reprodução social de valores de natureza técnica e científica incorporados no universo linguístico e representacional de classe de forma fragmentada (BOLTANSKI, 1974). Essa incorporação se dá via valores sociais e institucionais que os grupos de mães mantêm com o meio social geral e particular do qual participam. Trata-se, em suma, do que na linguagem de BOLTANSKI (1974), poderia apresentar-se como mecanismo de reinterpretação presente no processo de transferência (ou socialização) de um esquema de pensamento para outro que, no presente caso entcnde-se, não se apresenta como defasagem mas como concomitância.

Os sentidos atribuídos ao desenvolvimento infantil são complementados por uma rede de relações que aproximam os conceitos às práticas cotidianas. Essas relações são especificadas em função de três elementos: as práticas de socialização das crianças, presentes nas categorias "sistema de cuidados" e "comunicação"; o agente socializador, presente na categoria "família" em suas várias formas de expressão; das condições onde esse processo se dá, definidas nas categorias “ambiente" e "condições de vida”. Neste particular, um traço comum observado nos discursos maternos é a idcntificação do processo de socialização com o processo de desenvolvimento infantil, na medida em que, um dos valores básicos presentes nesse contexto de representações, trata-se da valorização da "adaptação social" da criança ao "ambiente" do qual participa. (Quadros 4, 5, 6).

As relações que se estabelecem nos sistemas particulares de unidades de sentido entre "unidades conceituais" e "aspectos associados" ao desenvolvimento, não se caracterizam pela linearidade e coerência mas, principalmente, pela contradição e ambigüidade presente nos discursos.

A ambiguidade e contradição implícita nas representações maternas, segundo o sugerido, encontra-se, ao lado da questão de classe, estreitamento relacionado ao caráter migratório, característico de parcela significativa da população de São Paulo, em especial da população residente nas zonas periféricas da cidade. Ao migrar, as famílias trazem para o contexto urbano industrial o sistema de valores c significados constitutivos de sua condição particular, vivida na sua rea- lidade social de origem (o meio rural ou urbano não industrializado). Esse capital cultural passa, por sua vez, por um processo de releitura em função da assimilação, maior ou menor, dos valores que caracterizam seu novo espaço de vida, no novo meio em que se inscreve. Esse processo de releitura não se dá pela simples anulação do capital cultural anterior, mas pela incorporação de novos valores, mesmo quando esses são conflitantes com os antcriores (BOLTANSKI, 1974). A situação de migração, ao que parece, determina uma contradição que se revela nos discursos maternos (SCOTT, 1988).

No processo observado ocorrem mudanças progressivas e explícitas no padrão educativo familiar, que se corporificam nas práticas vigentes em relação a cada nova fase do desenvolvimento infantil.

Cabe indicar que, marcadas pelos traços de ambiguidade e contradição, as representações maternas deixam transparecer questões importantes para a temática, objeto do presente estudo.

No que se refere as "práticas socializadoras”, estas se caractcri zam pelo privilegiamento das "práticas de limpeza”, em detrimento “das práticas de autonomia”. As práticas de limpeza são caracterizadas pelo aspecto higiênico da rotina infantil, expressas em atividades cotidianas como comer, controle de esfincter, dentre outras. Se por um lado, o desenvolvimento da autonomia implica no privilegiamento do aprendizado precoce, que objetiva a independência da criança, por outro, as práticas de limpeza privilegiam a higiene, mesmo que as custas do fortalecimento dos laços de dependência da criança em relação ao adulto. A autonomia não é uma preocupação marcante nas representações das mães, esta parece ser algo progressivo, que ocorre de forma alheia à intenção do adulto.

POSTER (1979), atribui à constituição do modelo dc família burguesa, tanto o privilegiamento dos hábitos de higiene e limpeza quanto a maior dependência na qual a criança é mantida. No entanto não se trata, no presente estudo, de famílias pertencentes à burguesia mas que reproduzem esse modelo de família. Podc-se supor que os contatos sociais mais frequentes, a submissão aos vcículos de comunicação de massa, além de um convívio próximo de famílias mais abastadas, propicie a interiorização de valores e costumes espcíficos das camadas médias da população.

As práticas socializadoras, operadas pela família através da relação mãe-criança, são marcadas pelo privilegiamento do brincar em oposição ao treinamento para o trabalho. Nas representações maternas os jogos simbólicos e o espaço da brincadeira estão incorporados enquanto 
elemento fundamental para o desenvolvimento infantil, bem como o direito ao estudo, enquanto estratégia ou possibilidade de ascensão social ou de não reprodução das condições de vida às quais as famílias estão submetidas.

O "contexto" e o "agentc socializador", categorias prcsentcs nas representações maternas, são caracterizados pela associação do desenvolvimento infantil às condições de vida, estas entendidas em suas formas objetiva e subjetiva. Neste grupo estão presentes a especificação objetiva e subjetiva da pertença a determinada classe social; disto deriva a noção de que o desenvolvimento infantil não se dá dc forma igual em crianças submetidas a condições sociais distintas, na medida em que a posição de classe se expressa não só por condições objetivas de vida, tais como alimentação, moradia, renda, mas também por condições subjctivas, tais como a disponibilidade afetiva da família, o capital cultural que esta dispõe para transmitir aos seus filhos.

Trata-se, portanto, de estruturas familiares características onde, no que se refere às relações de gênero, as mulheres têm um papel marcadamente doméstico já que, no grupo estudado, poucas mulheres exercem atividade remunerado, onde o dominio do espaço público é assegurado ao homem, assim como a responsabilidade pela manutenção material da familia. Às mulheres é reservado o espaço da casa, constituindo-se como a principal responsável pela educação e transmissão de valores aos filhos. A participação do pai nesse processo é pequena ou quase nula, reproduzindo, assim, o modelo tipico da familia burguesa descrita por POSTER (1979).

A situação analisada não é vivida de forma conflituosa pelas mães, ao menos nos discursos; ao contrário, observa-se nas representações sobre a figura paterna, a legitimação desse modelo de relações. Ao pai é reservado o espaço da rua, à mãe o dominio sobre a educação e, por implicação, sobre o desenvolvimento dos filhos.

No entanto, conforme afirma GOMES(1988), “como valores e costumes são adaptados às condições particulares de existência do grupo, esses recém-incorporados, aparecem transfigurados no eontexto dessas famílias”. A incorporação de novos padrões culturais obriga, progressivamente, as famílias a reestruturar sua identidade. Na medida em que incorporar o novo não implica, necessariamente, destruir o velho, ambos passam a conviver no mesmo indivíduo, no mesmo campo social - o grupo familiar. Isto pôde ser constatado ao se eomparar as representações das mães das duas instiluições estudadas. Entre as mães do grupo 1, essa incorporação de novos valores encontra-se em processo ainda re- cente, pina vez que muitas famílias migraram para São Paulo de outras regiões do país, há pouco tempo. No grupo II, esse processo parece estar mais consolidado, apesar de ainda apresentar traços e valores culturais típicos de regiões não metropolitanas.

O grupo familiar, responsável pelo desenvolvimento de seus filhos, acaba por exercer um papel onde a ambigüdade é o traço fundamental da experiência de vida das crianças. Estas são, ao mesmo tempo, fruto das experiências vividas por seus pais e avós e dos valores e condições específicas da periferia de um grande centro urbano como São Paulo.

\section{Saber Popular Versus Representações do Saber Técnico-Profissional}

As relações eslabclecidas cntre as práticas e as representações dos profissionais são complexas de qualquer ângulo de que as divisc. Dessa teia de relações participam, pelo menos três elementos: o ponto de vista do profissional sobre o objeto da sua prática (suas reprrsentações), o contexto institucional onde essa prática se desenvol$v e, e$ as demandas trazidas pela população atendida (suas representações).

No que se refere às representações dos profissionais e às demandas da população, pode-se dizer que estas mantêm entre si relações contraditórias porque, ora de cumplicidade, ora de oposição e conflito. Como afirma LEFEVRE, “o usuário ... vivendo numa dada sociedade, está sempre envolvido com o ponto de vista do social e com o ponto de vista dos médicos, em relações de submissão, rebeldia, hegemonia, etc.”. (LEFEVRE, 1989, p. 183)

A dinâmica particular que se forja no exercício cotidiano de uma determinada prática de saúde, no caso os processos de intervenção sobre a saúde da criança, é composta pelo ponto de vista do usuário - no presente trabalho as mães interagindo com a visão de mundo dos técnicos, configurando relações complexas de hegemonia, de alianças, de transgressão, de submissão, de poder e de contra poder.

A despeito da relativa aceitação da relação entre possuir conhecimento e deter poder, tal associação não se dá de forma mecânica no pensamento do senso comum. Afirma ADORNO a respeito: "o saber ocupa espaço importante na hierarquia que o senso comum constrói, ordenando quem pode mais ou quem pode menos. Este poder ... coloca-se na esfera do cotidiano, na esfera das relações entre as pessoas e as instituições, entre elas a saúde, a educação, os serviços públicos. O poder dizer sobre está próximo do prescrever para o outro e colocá-lo sob 
controle. Para o outro o poder está em usufruir desta relação com quem pode”.(ADORNO et al, 1987, p. 408)

Com efeito, o que se observa no presente trabalho a propósito da comparação das representações de mães sobre a atribuição de conhecimento sobre o desenvolvimento, com as representações dos profissionais sobre as motivações das práticas maternas, é que essa relação não se configura numa mera subordinação das primeiras às segundas: ao contrário, com frequência as representações maternas se caracterizam pelo questionamento e, por vezes, pela negação do conhecimento técnico-profissional. (Quadros 7, 8, 9)

Quanto às representações dos técnicos sobre as motivações matemas, pode-se afirmar que, de uma forma geral, os técnicos concebem as usuárias - mães - dos serviços de saúde como "aquelas pessoas que não sabem" em oposição aos "profissionais que detêm o saber".

Vale frisar, que em relação às mães, o desenvolvimento infantil é representado como terreno de conhecimento amplo, que extrapola os limites da arca de saúde e, portanto, do conhecimento acumulado pelos profissionais.

Observe-se que nas representações do senso comum a "autoatribuição de saber" sobre o processo dc desenvolvimento infantil configura o que ADORNO (1987) caracteriza como "conhecimento vivencial”. Para as mães, o desenvolvimento infantil é também entendido e representado como um campo de domínio próprio. Poder-se-ia dizer que trata-se de um campo onde as mães se vêem como sujeitos c, portanto, onde o seu conhecimento deve ser reconhecido.

Por outro lado, a ausência de tradição de uma prática médica em Saúde Pública voltada ao desenvolvimento infantil, visto em sua multiplicidade de aspectos, diferentemente da praticada pela tradicional puericultura, reforçam essa tese representada pelas mães em relação ao tema.

Tais constelações se opõem a trabalhos sobre o assunto, como por exemplo o de RODRIGUES (1983), onde a legitimidade do conhecimenlo materno é afirmada apenas em função do seu distanciamento do conhecimento científico, adotado como hegemônico.

A hipótese subjacente de autores dessa linha de pensamento é a de que a construção do conhecimcnto do senso comum se dá, apenas, pela informação passiva; ao conhecimento vivencial é negado o "status" de conhecimento, na medida em que a linguagem que o veicula utiliza signos próprios, nem sempre com similares no discurso científico. Isto pode ser evidenciado nas categorias de representação sobre o aspecto conceitual do desenvolvimento.

Relacionado a isso vale indicar, igualmente, a polêmica presente no campo da Teoria do Conhecimento acerca da questão "continuidade" e "descontinuidade" da relação ciência e senso comum. No presente trabalho, a postura adolada é a defendida por pensadores como WARTOFSKY (1976), que vê a relação ciência - senso comum não como ruptura, mas como formas difercnciadas de experiências em função dos recursos utilizados e propósitos prcsentes. À primeira cabe um saber crítico, sistemático, enquanto à segunda um saber prático sobre o qual a primeira se exerce no desvendar de suas estruturas e processos.

Acredita-se, assim, que a vivência de um dado problema pode se constituir numa modalidade legítima de conhecimento e que a relação técnico/usuário, presente no interior das ações dirigidas à promoção do desenvolvimento, configura uma contradição não antagônica entre sujeitos conhecedores: o sujeito técnico e o sujeito vivencial. Entende-se, portanto, que o conhecimento vivencial não deve ser anulado ou superado em favor do conhecimento técnico, mas que ambos devem ser observados numa relação tensional, dialétiea.

Considera-se que os serviços públicos de saúde - até para a sobrevivência como instituição - deve recuperar os fundamentos legitimam as suas práticas. Esta legitimidade pode ser vislumbrada na medida em que a tensão dialética acima referida, possa se transformar em força motriz que movimcnte, tanto a prática profissional quanto o conhecimento que a sustenta, quanto o conhecimento vivencial que ambos se dissolvam numa unidade híbrida (ADORNO, et al. 1987). isso implica tornar, através dessa tensão dialética, mais real, porque mais vivido, o conhecimento técnico sobre o desenvolvimento da criança, e tornar mais técnico - ou mais sistemático - o conhecimento vivido por mães desse mesmo processo. 


\section{BIBLIOGRAFIA}

01. ADORNO, R C. F. et al. O conhecimento e o poder: de quem é a palavra Relato de urna experiência de pesquisa participante. Rev. Saúde Públ., S. I’aulo, 21: 4115-12, $19 X 7$.

02. ALVARENGA, A. T. Reflexões acerca da Abordagem Sociológica do Crescimento e do Desenvolvimento da Criança no Campo da Saúde Pública: Aspectos Teorico-Metodológicos. Rev. Bras. Cresc. Des. Hum., São Paulo, 1(2), 1991.

03. ALTHUSSER. L. Ideologia e aparelhos ideológicos de Estudo. Lisboa, Editorial Presença, 1980.

04. BOLTANSKI, L. Puericultura y moral de clase. Barcelona, Laia. 1974.

05. BOURDIEU, P. A economia das trocas simbólicas. São Paulo. Pcrspcctiva, 1974.

06. BOURDIEU, P. O poder simbólico. Rio de Janeiro. Difel/Bertrand, 1989.

07. BOURDIEU, P, Questões de sociologia. Rio de Janeiro. Marco Zero. 1983.

08. BRIOSCIH. I. R; TRIGO, M. H. H. Família: Representação e cotidiano. Textos CERU. São Paulo. 1(2 ). 1989.

09. GOMES, J. V. Do campo à cidade: As transformações nas práticas educativas familiares. Cad Pesq. São Paulo, ed.: 48-56. 1988.

10. LEFÈVRE. F. O medicamento como problema de saúde pública: Contribuição para o estudo de uma mercadoria simbólica. São Paulo. 1989. [Tese de Doutoramento. Faculdade de Saúde Pública / USP].
11. OLIVEIRA. D. C. O Desenvolvimento lnfantil e suas Represenhções: Dimensões do Saber Técnico Profissional e do Senso Comum. São Paulo, 1991. [Monografia de Mestrado - Faculdade de Saude Púhlica / USP].

12. POSTER, M. Teoria crítica da família. Rio de Janeiro. Zahar. 1979.

13. RODRIGUES. K. H. Conhecimentos das mães sobre os fatores que influem no desenvolvimento de seus filhos. São Paulo, 1983. [Dissertação de Mcstrado - Escola de Enfermagem / USP].

14. SCOTT. R. R. Comparáveis ou incomparáveis? Famílias de trabalhadores rurais, pobres urbanos e classe média: Um roteiro de pesquisa sobre o uso social do trabalho. In Seminário: Nordeste o que há de novo?. Rio Grande do Norte. p 45-56. 1988. [Mimeografado].

15. SPINK, M. J. P. As representações sociais e sua aplicação em pesquisa na área de saúde. 2 Congresso Brasileiro de Saúde Coletiva e 3 Congresso Paulista de Saúde Pública. ABRASCO/APSP. São Pnulo, 3-7 jul. 1989. [Aula proferida no curso "Trabalhando com os conceitos de coletivo, representação social, participação e cidadania em saúde” mimeografado].

14. WARTOFSICY, M. W. Introducción a la Filosofia de la Ciencia. Madrid, Editora Alianza Universidad. 1976. 


\section{ANEXOS}

QUADRO 1: REPRESENTAÇÕES DO SENSO COMUM SOBRE O ASPECTO CONCEITUAL DO DESENVOLVIMENTO INFANTIL

\begin{tabular}{|c|c|c|}
\hline \multicolumn{3}{|c|}{ SISTEMA ARTICULADO DE UNIDADES DE SENTIDO } \\
\hline $\begin{array}{l}\text { NÚCLEO ESTRUTURADOR } \\
\text { DOS DISCURSOS DO SENSO } \\
\text { COMUM }\end{array}$ & $\begin{array}{l}\text { CATEGORIAS GERAIS DE } \\
\text { DISCURSO }\end{array}$ & $\begin{array}{c}\text { CATEGORIAS ESPECIFICAS E GRUPOS } \\
\text { TEMÁTICOS }\end{array}$ \\
\hline \multirow{15}{*}{$\begin{array}{l}\text { REPRESENTAC̄ÕES } \\
\text { SOBRE O ASPECTO } \\
\text { CONCEITUAL DO } \\
\text { DESENVOLVIMENTO INFANTIL }\end{array}$} & A - Desenvolvimento é "TUDO" & $\begin{array}{l}\text { - inclui crescimento (aumento de tamanho) } \\
\text { - inclui as dimensões física, mental, social e } \\
\text { afetiva equilibrio entre fisico e mental) } \\
\text { - concepção de processo; apreensão do } \\
\text { mundo e o relacionar-se com ele } \\
\text { - "ocorre no mundo"; implica em certo grau } \\
\text { de naturalidade do desenvolvimento }\end{array}$ \\
\hline & & - organismo biológico predominante \\
\hline & B - Desenvolvimento é "SAÚDE" & $\begin{array}{l}\text { - crescimento do organismo (fisico) e da } \\
\text { mente (inteligência e esperteza) } \\
\text { - inclui crescimento (aumento de tamanho) }\end{array}$ \\
\hline & & $\begin{array}{l}\text { - saúde da mente é extensão da saúde do } \\
\text { organismo }\end{array}$ \\
\hline & & - não inclui crescimento físico \\
\hline & & - "a mente aumenta de tamanho" \\
\hline & & - mente é igual a inteligência \\
\hline & $\begin{array}{l}\text { C - Desenvolvimento é o } \\
\text { "CRESCIMENTO DA MENTE E } \\
\text { A INTELIGÊNCIA }\end{array}$ & $\begin{array}{l}\text { - inteligência se expressa por: imitação, } \\
\text { esperteza, aprendizagem, compreensão das } \\
\text { comunicações verbais, capacidade de } \\
\text { realizar coisas }\end{array}$ \\
\hline & & $\begin{array}{l}\text { - mente é um "depositário que armazena } \\
\text { informações" } \\
\text { - a inteligência possibilita a socialização }\end{array}$ \\
\hline & & - não inclui crescimento fisico \\
\hline & & $\begin{array}{l}\text { - inclui comportamentos psico-motores - } \\
\text { sociais }\end{array}$ \\
\hline & $\begin{array}{l}\text { C - Desenvolvimento é "GASTAR } \\
\text { ENERGIA E } \\
\text { CONHECER O MUNDO" }\end{array}$ & $\begin{array}{l}\text { - a criança é um "depositário de energia" } \\
\text { mental e fisica } \\
\text { - a utilização da energia (condutas motoras) } \\
\text { leva à aprendizagem intelectual e motora eà } \\
\text { socialização }\end{array}$ \\
\hline & & - não inclui crescimento físico \\
\hline & $\begin{array}{l}\text { D- Desenvolvimento é a } \\
\text { "RESPOSTA DAS CRIANCCAS } \\
\text { AOS ESTIMULOS DO MEIO }\end{array}$ & $\begin{array}{l}\text { - inclui as dimensões } \\
\text { emocional/social/mental } \\
\text { - caráter normativo dos comportamentos }\end{array}$ \\
\hline & $\begin{array}{l}\text { AMBIENTE E A EVOLUÇÃO } \\
\text { DA IDADE" }\end{array}$ & $\begin{array}{l}\text { - agilidade no aparecimento de respostas } \\
\text { (comportamentos) aos estímulos recebidos } \\
\text { - articulação da concepção inata (natural) } \\
\text { com a ação do meio social }\end{array}$ \\
\hline
\end{tabular}


QUADRO 2: REPRESENTAÇÕES DOS PROFISSIONAIS SOBRE O ASPECTO CONCEITUAL DO DESENIOLIIMENTO INFANTIL

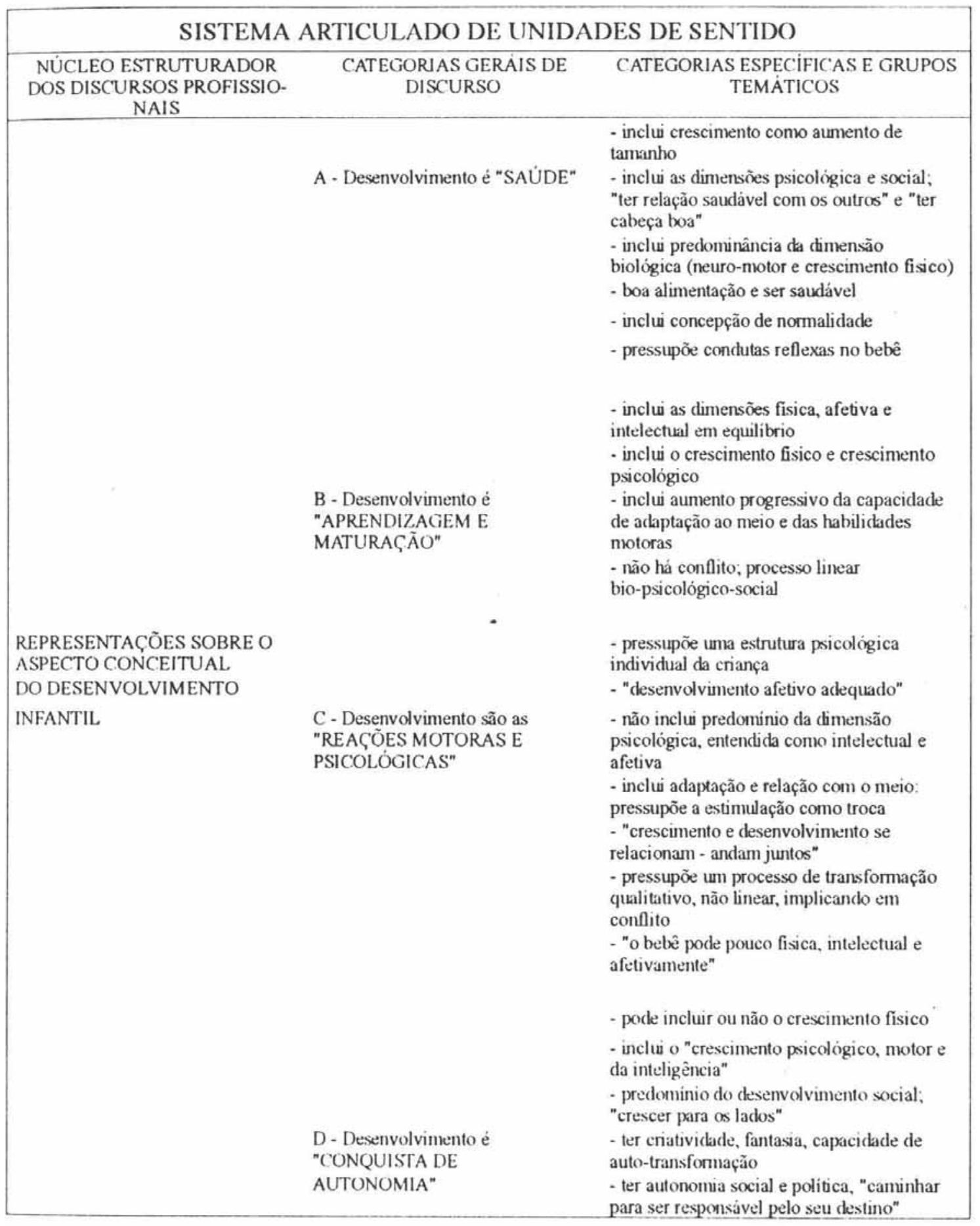


QUADRO 3: CATEGORIAS EMPÍRICAS DO ESTUDO SEGUNDO CONCEPÇOEES CIENTIFICAS

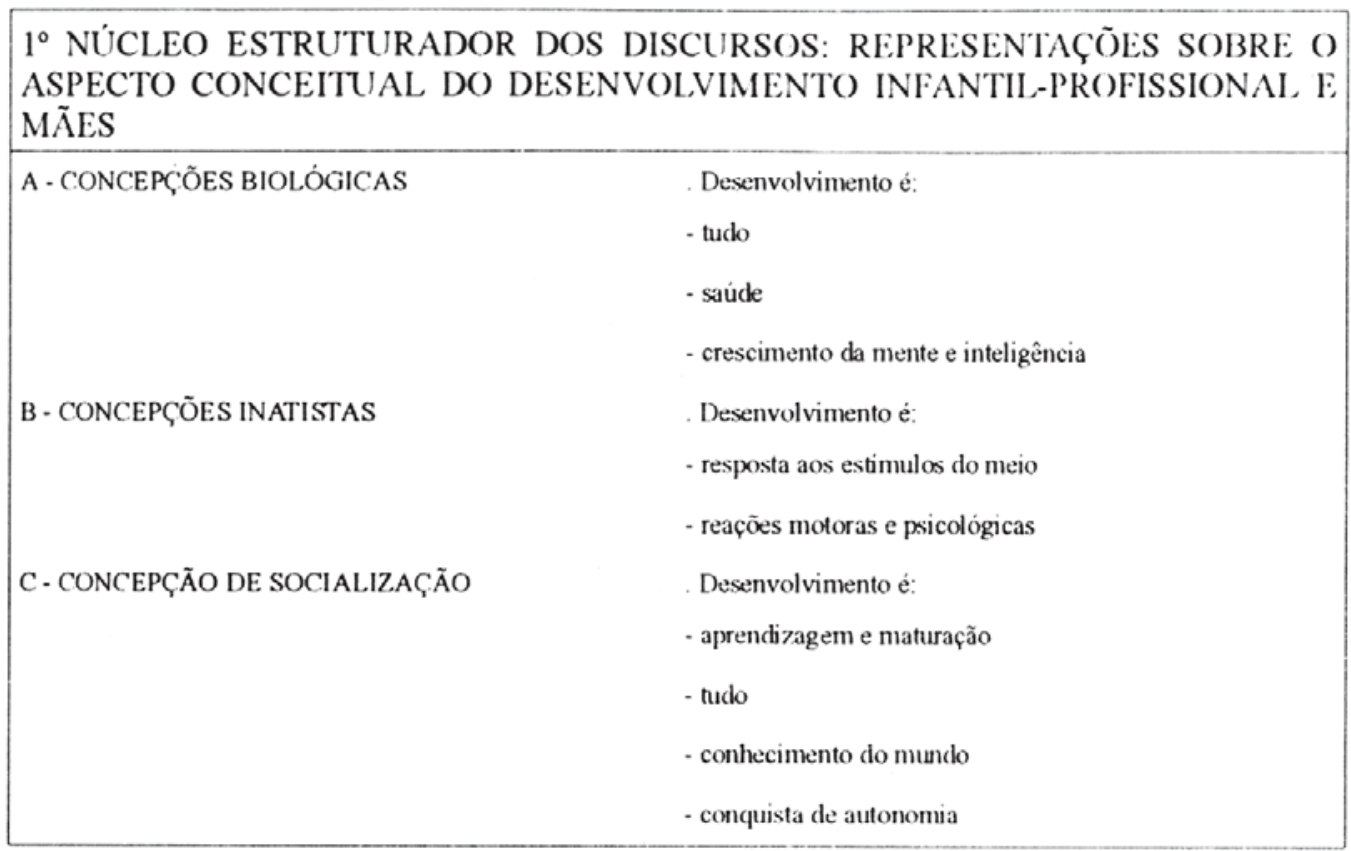

QUADRO 4: REPRESENTAÇÕES DO SENSO COMUM SOBRE AS DETERMINAÇÕES DO DESENVOLVIMENTO INFANTIL

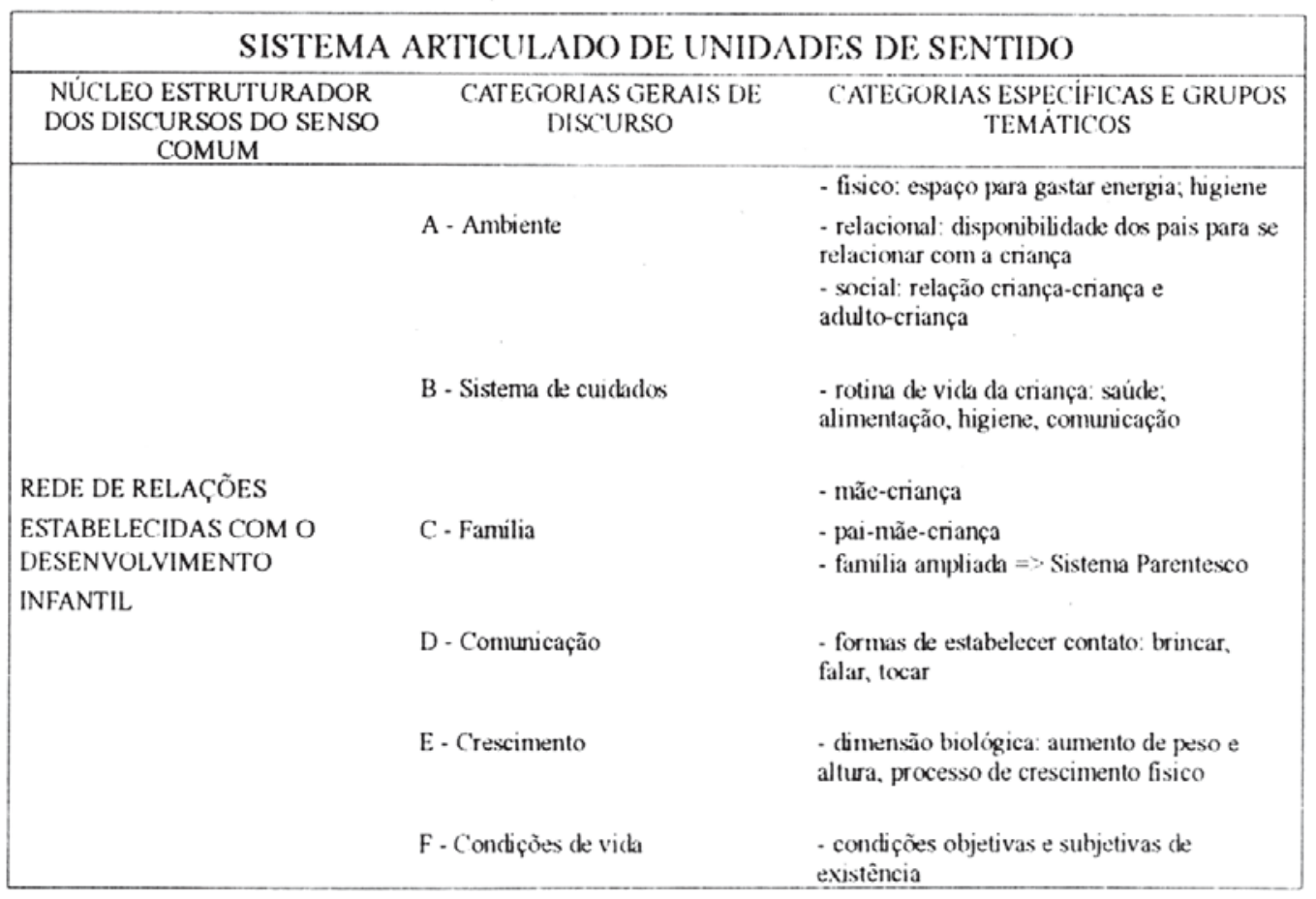


QUADRO 5: REPRESENTAÇÕES DOS PROFISSIONAIS SOBRE AS DETERMINAÇÕES DO DESENVOLITIENTO INFANTIL

\begin{tabular}{|c|c|c|}
\hline \multicolumn{3}{|c|}{ SISTEMA ARTICULADO DE UNIDADES DE SENTIDO } \\
\hline $\begin{array}{l}\text { NÚCLEO ESTRUTURADOR } \\
\text { DOS DISCURSOS DOS PROFIS- } \\
\text { SIONAIS }\end{array}$ & $\begin{array}{l}\text { CATEGORIAS GERAIS DE } \\
\text { DISCURSO }\end{array}$ & $\begin{array}{c}\text { CATEGORIAS ESPECIFICAS E GRUPOS } \\
\text { TEMÁTICOS }\end{array}$ \\
\hline \multirow{11}{*}{$\begin{array}{l}\text { REDE DE RELAÇÕES } \\
\text { ESTABELECIDAS COM O } \\
\text { DESENVOLVIMENTO INFANTIL }\end{array}$} & A - Condições de Vida & $\begin{array}{l}\text { - condições materiais de existência: } \\
\text { financeira, moradia, alimentação, saúde, } \\
\text { trabalho }\end{array}$ \\
\hline & & - constituição orgânica adequada \\
\hline & B - Condições de Saude & - estado nutricional \\
\hline & & - presença de doença \\
\hline & & $\begin{array}{l}\text { - espaço fisico: disponibilidade de moradia, } \\
\text { espaço para brincadeiras }\end{array}$ \\
\hline & C - Ambiente & $\begin{array}{l}\text { - espaço social: experiências sociais com a } \\
\text { familia ampliada e pessoas que convivem } \\
\text { com a criança }\end{array}$ \\
\hline & & $\begin{array}{l}\text { - espaço relacional: possibilidade de } \\
\text { estabelecer vínculos com a familia nuclear }\end{array}$ \\
\hline & D - Estimulos do meio & $\begin{array}{l}\text { - disponibilidade dos adultos para se } \\
\text { relacionarem com a criança - "forma de } \\
\text { cuidar" }\end{array}$ \\
\hline & & - escola \\
\hline & E - In tituições sociais & - creche \\
\hline & & - serviços de saúde \\
\hline
\end{tabular}
QUADRO 6: CATEGORIAS EMPIRICAS DO ESTUDO SEGUNDO CONCEP-
ÇOEES CIENTIFICAS

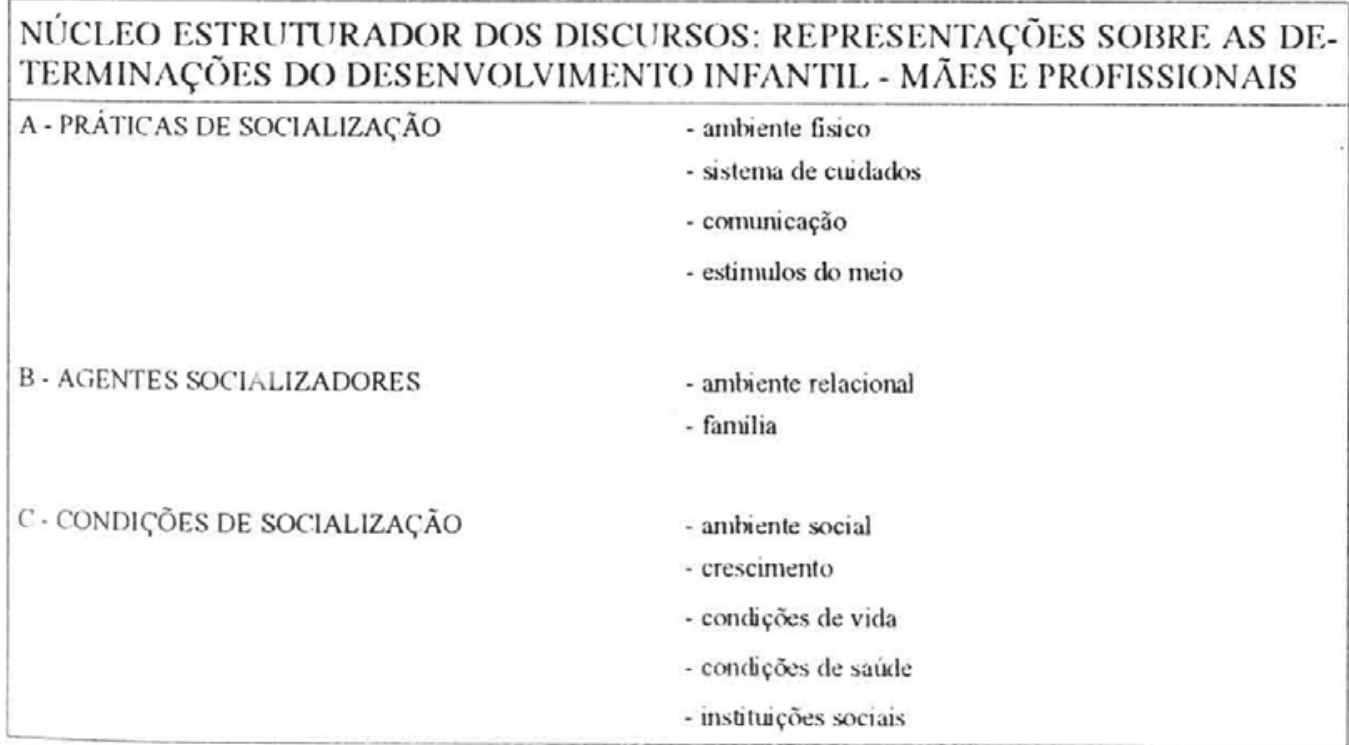


QUADRO 7: REPRESENTACÕES DO SENSO COMUM SOBRE A ATRIBUIÇÃO DE CONHECIMENTO SOBRE O DESENVOLVIMENTO DA CRIANÇA

\begin{tabular}{|c|c|c|}
\hline \multicolumn{3}{|c|}{ SISTEMA ARTICULADO DE UNIDADES DE SENTIDO } \\
\hline $\begin{array}{l}\text { NÚCLEO ESTRUTURADOR } \\
\text { DOS DISCURSOS DO SENSO } \\
\text { COMUM }\end{array}$ & $\begin{array}{l}\text { CATEGORIAS GERAIS DE } \\
\text { DISCURSO }\end{array}$ & $\begin{array}{c}\text { CATEGORIAS ESPECÍFICAS E GRUPOS } \\
\text { TEMÁTICOS }\end{array}$ \\
\hline \multirow{5}{*}{$\begin{array}{l}\text { ATRIBUIÇÃO DE } \\
\text { CONHECIMENTO SOBRE } \\
\text { O PROCESSO DE } \\
\text { DESENVOLVIMENTO INFANTIL }\end{array}$} & A - Atribuição de poder - pelo & - auto-atribuição de conhecimento \\
\hline & saber - a mães & $\begin{array}{l}\text { - conhecimento reconhecido em outras mães } \\
\text { - médicos pediatras }\end{array}$ \\
\hline & $\begin{array}{l}\text { B - Atribuição de poder - pelo saber } \\
\text { - a categorias profissionais }\end{array}$ & $\begin{array}{l}\text { - profissionais universitários (psicólogos e } \\
\text { nutricionistas } \\
\text { - pessoas com capacidade de conunicação } \\
\text { (autoridade inespecifica - conhecimento } \\
\text { informal) }\end{array}$ \\
\hline & & - universo social geral \\
\hline & $\begin{array}{l}\text { C - Atribuição de poder - pelo saber } \\
\text { - a instituições sociais }\end{array}$ & $\begin{array}{l}\text { - universo institucional (centros de saúde, } \\
\text { creches e escolas) } \\
\text { - universo de relações sociais primárias }\end{array}$ \\
\hline
\end{tabular}

QUADRO 8: REPRESENTAÇÕES DOS PROFISSIONAIS SOBRE AS MÃES USUÁRIAS DOS SERVIÇOS DE SAÚDE

\begin{tabular}{|c|c|c|}
\hline \multicolumn{3}{|c|}{ SISTEMA ARTICULADO DE UNIDADES DE SENTIDO } \\
\hline NÚCLEO ESTRUTURADOR & CATEGORIAS GERAIS DE & CATEGORIAS ESPECÍFICAS E GRUPOS \\
\hline $\begin{array}{l}\text { DOS DISCURSOS DOS PROFIS- } \\
\text { SIONAIS }\end{array}$ & DISCURSO & TEMÁTICOS \\
\hline \multirow{4}{*}{$\begin{array}{l}\text { REPRESENTAÇÕES SOBRE } \\
\text { AS MÃES USUÁRIAS DOS } \\
\text { SERVIÇOS DE SAÚDE }\end{array}$} & A-Desamparadas socialmente & $\begin{array}{l}\text { - maternidade sem amparo social } \\
\text { - culpabilização social das mães }\end{array}$ \\
\hline & & - privação cultural \\
\hline & B - Carentes e Limitadas & $\begin{array}{l}\text { - postura assistencialista } \\
\text { - necessitadas de informação }\end{array}$ \\
\hline & $\begin{array}{l}\mathrm{C} \text { - Interessadas e com experiências } \\
\text { para trocar }\end{array}$ & $\begin{array}{l}\text { - conhecimento construido a partir da } \\
\text { experiência cotidiana } \\
\text { - adesão às propostas dos serviços de saúde, } \\
\text { na medida da confiança que depositam neles }\end{array}$ \\
\hline
\end{tabular}
QUADRO 9: CONFRONTAÇÃO DAS CATEGORIAS EMIPÍRICAS DE MÃES E
PROFISSIONAIS

$3^{\circ}$ NÚCLEO ESTRUTURADOR DOS DISCURSOS: ATRIBUIÇÃO DE CONHECIMENTO SOBRE O PROCESSO DE DESENVOLVIMENTO - CORRELAÇÃO ENTRE PROFISSIONAIS E MÃES

CATEGORIAS DO SENSO COMUM CATEGORIAS PROFISSIONAIS
MÃES $\longrightarrow$ MÃES INTERESSADAS E COM EXPERIÊNCIAS PARA TROCAR

violência simbólica

PROFISSIONAIS $\longrightarrow$ CARENTES E LIMITADAS

INSTITUIÇÕES SOCIAIS — MÃES DESAMPARADAS SOCIALMENTE 